\title{
INVESTIGATION OF LACTATE, HEART RATE AND HANDGRIP FORCE RESPONSES OF CLIMBERS
}

\author{
CEMIL CAGLAR BILDIRCIN \\ Department of Training Sciences, Faculty of Sport Sciences, Akdeniz University, Turkey
Mailing address: Cemil Caglar Bildircin, Akdeniz University, Department of Training Sciences, Akdeniz Üniversitesi Street; 07070 Konyaaltı/Antalya, Turkey, e-mail: ccbildircin@gmail.com

\begin{abstract}
Introduction. Sport climbing, which is included in 2020 Olympic Games, is a new sport that is both recreational and performance-focused while being the subject of scientific research all around the world. The aim of this study was to analyze the changes in lactate concentration, heart rate and handgrip forces all at once in the actual sport climbing competition. Material and Methods. Thirteen male climbers volunteered for this study. The climbers climbed three different routes prepared according to the International Federation of Sport Climbing standards that are classified as easy, medium and difficult. Lactate, heart rate, dominant and non-dominant handgrip forces were measured for each route before climbing, immediately after, and during the third and fifth minutes after climbing. Climbing performance was determined using the number of holds that the competitor reached. Results. We observed significantly higher post-lactate concentration in comparison to the pre-climbing values for all climbing routes $(\mathrm{p}<0.05)$. Statistical observation shows that post-climbing heart rate values were considerably higher than the pre-climbing values for all three climbing trials $(\mathrm{p}<0.05)$. There were also statistically significant differences in climbing performance and handgrip force between the three routes $(\mathrm{p}<0.05)$. Conclusions. According to the results of this study, significant increases were noted in all three climbing routes relative to the pre-climb in lactate, heart rate and climbing performance data between the routes.
\end{abstract}

Key words: Olympic games, sport climbing, competition, climbing performance

\section{Introduction}

Sport climbing, both as the subject of scientific research and a performance sport, has become increasingly popular worldwide recreationally as well as in the elite performance sport category $[1,2]$. Sport climbing, which has its own specific characteristics, requires high physical competence and gymnastic type acrobatic movements [3]. Not only natural rocks but also indoor climbing walls can be used both for competition and training. However, international level circuit of climbing competitions, such as World Cups and Championships, take place on artificial climbing walls [3].

It is well known that the physical activity of sport climbing during most of the ascent is terminated between two and three minutes $[4,5]$. This aspect of climbing may also be why climbing is described as a short duration high-intensity exercise. This type of exercise dominantly uses anaerobic pathway and glycolysis as a dominant source of energy for muscle contraction [5]. Thus, as a result of glycolysis, the concentrations of lactic acid in the blood will tend to increase as long as the high-intensity exercise continues.

Upper body anaerobic strength and endurance are two of the most important components that determine sport climbing performance [6]. With this in mind, there are some physical and physiological differences between elite and non-elite climbers such as anthropometry features, finger strength, flexibility, handgrip force, aerobic and work capacity $[7,8]$.

Upper body carries a large majority of the body weight during climbing [2]. In doing so, especially forearm muscles contract isometrically [9]. The basic mechanical feature of the climbing is that while one arm carries a part of the body weight on a hold, the other arm has to move to the next hold. This means one arm has to carry a considerable part of the body weight while the other is moving. With the use of small handholds, footholds and overhanging climbing surface techniques which make climbing difficult, upper body load increases especially on the forearm [10]. Such factors that increase the difficulty of sport climbing will negatively affect both lactate concentration and the ability of contraction of the forearm muscles due to the increased exercise intensity and fatigue [11]. This physiological process may define the local fatigue of climbing effort. However, failing during climbing may not be related to the lactate concentration alone.

Handgrip force (HGF) may be an important factor that is associated with climbing performance even though measurements of it may lack climbing specificity because of the difference between the dynamometer and holds grip. Many scientific studies have shown that climbers have higher handgrip force values than non-climbers $[12,13]$. A study that simulates the competition conditions has shown that HGF decreases significantly at one-minute post-climbing compared to the pre-climbing value [2]. However, the results of this study which was conducted to determine how post-climbing HGF changes depending on time for each arm was not encountered especially in a competition setting.

There is a limited number of studies in which lactate concentrations, HGF and heart rate of sport climbers are measured all at once. In particular, the number of studies in a real competition setting is negligible. Most of these studies were conducted to determine climbing performance by measuring the changes of these variables in simulated conditions. Hence, the purpose of the present study was to investigate climbers' lactate concentration, HGF and heart rate response on three different levels of climbing routes in a real competition setting.

\section{Material and Methods}

Thirteen male competitive sport climbers (mean \pm SD; age $23.4 \pm 4.5$ years, height $1.74 \pm 0.06 \mathrm{~cm}$, weight $62.8 \pm 8.6 \mathrm{~kg}$ ) volunteered to participate in the present study. Some charac- 
teristics of the climbers were defined in accordance with the position statement by IRCRA [14]. The climbers saw themselves predominantly as sport climbers and except for one male, all of them were right-handed. Their self-reported training regimens for the last six months were 2-5 days/week, $3.5 \pm 1.6$ hours per day per season (mean $\pm \mathrm{SD}$ ). Climbing ability of the subjects was self-reported and was noted as on-sight and red-point. On-sight climbing performance (OCP) was defined as the highest grade climbed without any falls in the first attempt with no beta or prior knowledge of the route [15]. 3:3:6 ratio was used to define red-point climbing performance (RCP) of the climber which is defined as the climbers' highest grade for which they have successfully climbed 3 times on 3 different routes within 6 months [16]. The OCP and RCP ability of climbers ranged between $6 a-7 c$ (IRCRA 11-21) and 6c-8b (IRCRA 15-25) in quantitative Frenchsport scale respectively. All participants were informed both orally and in writing of the purpose and the risks of the research, and gave their written consent to participate prior to beginning the investigation. The study was performed in accordance with ethical standards in sport and exercise science research [17].

All the measurements were realized at the Cukurova University $4^{\text {th }}$ Sport Climbing Competition which was held on an indoor climbing wall. The climbing wall was $12.5 \mathrm{~m}$ in height, $10 \mathrm{~m}$ in width and $5 \mathrm{~m}$ overhang in total. There were three routes in the competition, 6a (27 holds), 6c (25 holds) and 7a+ (28 holds) French-sport scale grades respectively (IRCRA 11, 15 and 18). Climbing performance (CP) was determined as the number of holds each competitor reached as outlined in the rules book of the International Federation of Sport Climbing (IFSC) [18]. All the climbers had one chance to attempt every single route and climbs were performed in ascending order of difficulty. To ensure that current resting baseline condition was achieved, rest periods during the study between attempts were minimum thirty minutes [19]. The routes were designed by a national route setter and grade confirmations were documented by two national level climbers with fifteen years of experience. Flash-technique was used in the study where the route setter demonstrates how to climb the route at the beginning of the competition, and then all the climbers could watch each other's performances.

Pre-climbing blood samples ( $\left.\mathrm{La}_{\mathrm{Pre}}\right)$, heart rates $\left(\mathrm{HR}_{\mathrm{Pre}}\right)$ and hang grip ( $\left.\mathrm{HG}_{\mathrm{Pre}}\right)$ force measurements were taken while the climbers were on the waiting bench before their climbing trials. Post-climbing heart rate $\left(\mathrm{HR}_{\text {Post }}\right)$ and hand grip $\left(\mathrm{HG}_{\text {Post }}\right)$ forces were measured and blood samples $\left(\mathrm{LA}_{\text {Post }}\right)$ were collected immediately after climbing (when the climber fell or climbed the route and rappelled down with the help of a belayer, untightened the knot and was accompanied to the chair by one of the employees of the measurement organization). Post-climbing measurements were repeated at the $3^{\text {rd }}\left(\mathrm{LA}_{3}, \mathrm{HG}_{3}, \mathrm{HR}_{3}\right)$ and $5^{\text {th }}$ minutes after climbing $\left(\mathrm{LA}_{5}, \mathrm{HG}_{5}, \mathrm{HR}_{5}\right)$. All measurements were collected for every single route. A sterile automatic lancet was used to make a small incision in the ear lobe and $20 \mu \mathrm{l}$ capillary bloods were collected into a heparinized capillary tube. The blood was transferred to an Eppendorf tube and then analyzed using EKF Diagnostic brand Biosen C-Line model lactate and a glucose analyzer. The analyzer was calibrated and checked using standard solution prior to the analysis. Heart rate (bts $\left.\cdot \mathrm{min}^{-1}\right)$ and handgrip forces were tested with PlusMED (PM-100B) and LAFAYETTE brand devices respectively [20]. Handgrip relative strength was computed as the ratio of absolute grip ( $\mathrm{kg}$ ) to body mass to allow comparison of the results from other studies.

\section{Statistics}

The normality of the data was examined by assessing the Kolmogorov-Smirnov goodness of fit testing on all the measured variables. The results indicated that all the measured variables followed normality. One-way analysis of variance with repeated measures was used to see changes of lactate, hand grip force and heart rate across the three climbing routes. Bonferroni post hoc test was applied to see if any of them significantly differed from others. Statistical significance was accepted as $\mathrm{p}<0.05$. Data was presented as mean and standard deviation (mean \pm SD) and the analysis was performed in Statistical Package for Social Sciences software package (SPSS, IBM, and Version 21.0).

\section{Results}

Considering the climbers' $\mathrm{CP}$, it seems that $100 \%$ success was achieved in the first route for all climbers (27.0 \pm 0 holds). Even so, an increase in the lactate concentrations of the climbers' post-climbing, $3^{\text {rd }}$ and $5^{\text {th }}$ minutes after climbing was about 3.4, 4.2 and 4 times higher than pre-climbing values, respectively. CP for the second and third route was $20.0 \pm 5.5$ holds of 25 holds (6c route) and $14.1 \pm 8.0$ holds of 28 holds route (7a+ route), respectively. There were statistically significant differences in $\mathrm{CP}$ between the three routes $(\mathrm{p}<0.05)$.

Lactate concentration data for the three routes is shown in Figure 1. There were no significant differences between pre-climbing lactate values of the three climbing trials. However, higher post-climbing lactate concentration on the second route was significantly different from the lactate concentration of the first route $(\mathrm{p}<0.05)$. We observed significantly higher post, $3^{\text {rd }}$ and $5^{\text {th }}$ minutes' lactate concentration in comparison to the pre-climbing values for all climbing trials $(\mathrm{p}<0.05)$.

The mean pre-climbing heart rate values of all climbing trials were similar and we found no significant differences in the data (Fig. 2). However, the statistical observation shows that post-climbing heart rate values were considerably higher than

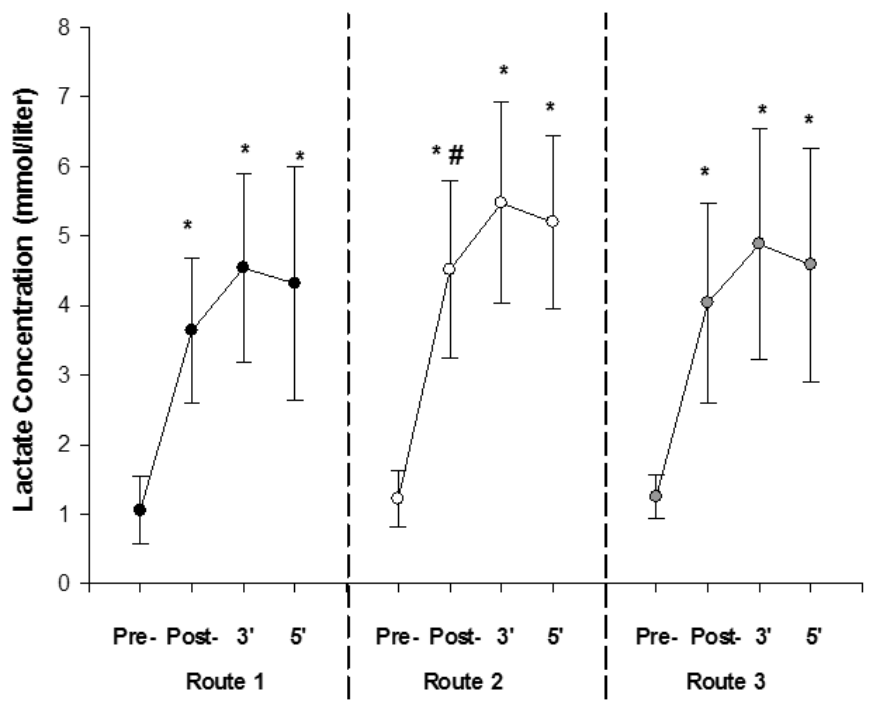

* - significantly higher than pre-climbing values $(\mathrm{p}<0.05)$;

$\#$ - significantly higher than post-climbing values of 1st route $(\mathrm{p}<0.05)$.

Figure 1. Blood lactate concentration $\left(\mathrm{mmol} \cdot \mathrm{L}^{-1}\right)$ pre-climbing (Lapre), post-climbing (Lapost), $3^{\text {rd }}\left(\mathrm{La}_{3}\right)$ and $5^{\text {th }}$ minutes $\left(\mathrm{La}_{5}\right)$ after climbing in $1^{\text {st }}, 2^{\text {nd }}$ and $3^{\text {rd }}$ route 
the pre-climbing values for all three climbing trials $(\mathrm{p}<0.05)$. $3^{\text {rd }}$ and $5^{\text {th }}$ minutes' heart rate values were statistically lower than post-climbing values in all climbing routes $(\mathrm{p}<0.05)$.

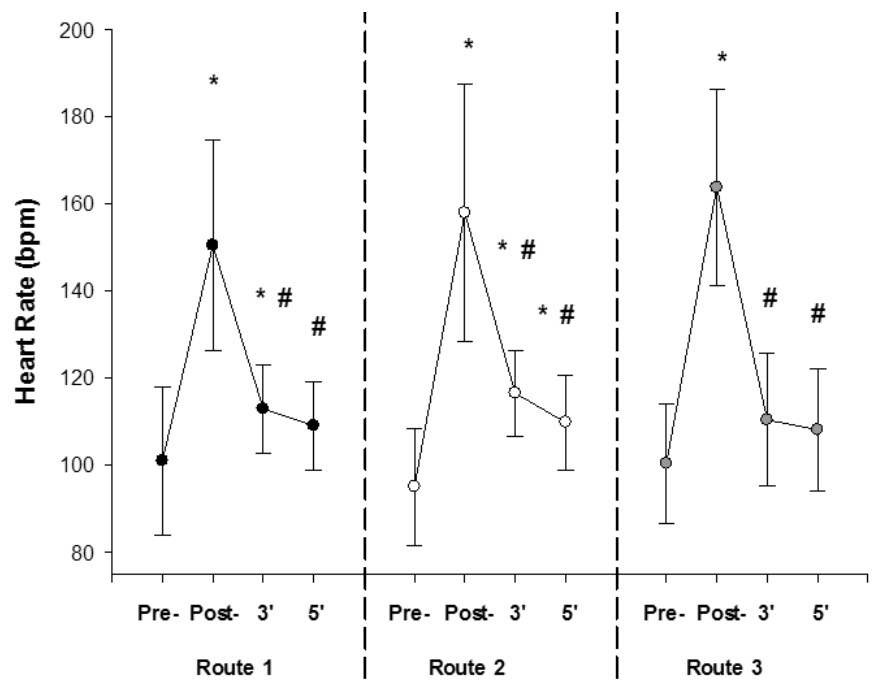

* - significantly higher than pre-climbing values $(\mathrm{p}<0.05)$;

$\#$ - significantly lower than post-climbing values $(\mathrm{p}<0.05)$.

Figure 2. Heart rate values (bts· $\left.\mathrm{min}^{-1}\right)$ pre-climbing $\left(\mathrm{HR}_{\mathrm{Pre}}\right)$, postclimbing $\left(\mathrm{HR}_{\text {Post }}\right), 3^{\text {rd }}$ minute $\left(\mathrm{HR}_{3}\right)$ and $5^{\text {th }}$ minute $\left(\mathrm{HR}_{5}\right)$ after climbing in $1^{\text {st }}, 2^{\text {nd }}$ and $3^{\text {rd }}$ route

Handgrip force values of right and left hands are shown in Figures 3 and 4, respectively. We found no significant difference in pre-climbing HGF values between the routes for the right or left hand. Force decrements on the first route were not statistically significant either for the right or the left hand. However, this was not the case for the second and third route. Statistically significant decrements were observed on the post-climbing and $3^{\text {rd }}$ minute values on second and third routes' right hands HGF ( $\mathrm{p}<0.05$ ). Moreover, second route post-climbing HGF values were the only significant force decrements for the left hand $(\mathrm{p}<0.05)$.

\section{Discussion}

To the best of our knowledge, this is the first study to analyze lactate, handgrip force and heart rate all at once in a real sport climbing competition setting. Various other studies have examined the lactate concentration of sport climbers in a simulated situation except for a study of Gaspari et al. [25]. In the study of Gaspari et al., lactate concentration was the only physiological parameter examined. Hence, the purpose of this study was to investigate lactate, handgrip force and heart rate response of rock climbers to the three different level climbing trials in a real competition setting.

In the present study, measured post-climbing lactate concentrations were higher when compared to the pre-climbing values of the $1^{\text {st }}, 2^{\text {nd }}$ and $3^{\text {rd }}$ route. Even though our results were lower than the results of Gaspari et al., this may be mainly due to the different exercise intensities of the climbing routes including the angle of the climbing wall and/or type of holds [25]. In Gaspari's study, routes were shorter and harder when compared to our study (17 holds 7a+ vs. 25 holds $6 \mathrm{c}$ and 20 holds $8 a$ vs. 28 holds $7 a+$ for semi-final and final, respectively). This may

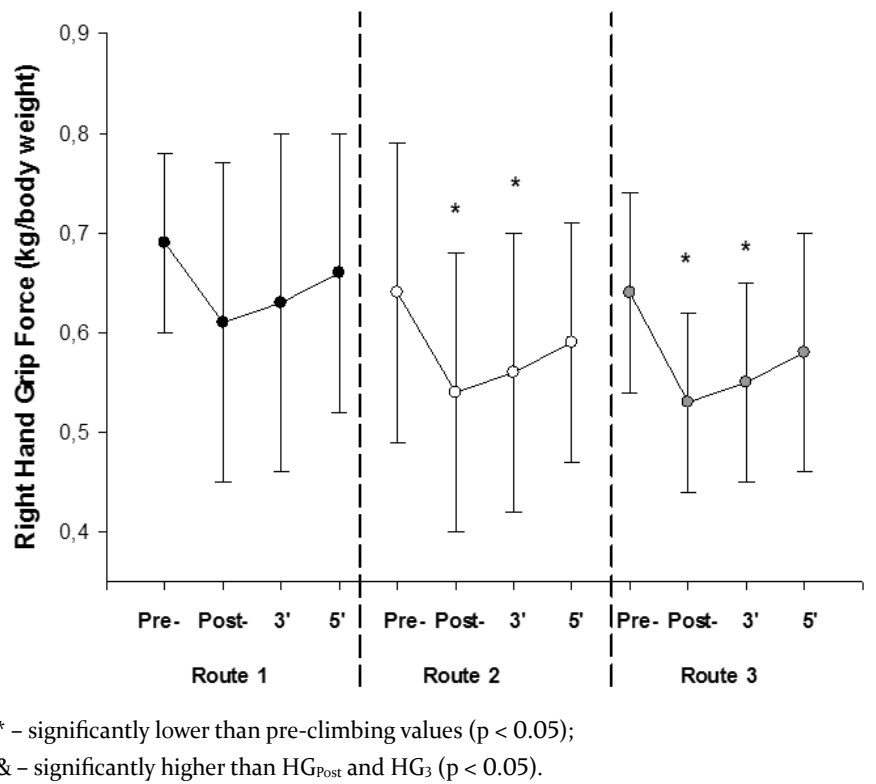

Figure 3. Mean values $( \pm \mathrm{SD})$ of the right hand grip force values pre-climbing $\left(\mathrm{HG}_{\text {Pre) }}\right.$ and post-climbing $\left(\mathrm{HG}_{\text {Post }}\right)$, $3^{\text {rd }}$ minute $\left(\mathrm{HG}_{3}\right)$ and $5^{\text {th }}$ minute $\left(\mathrm{HG}_{5}\right)$ after climbing in $1^{\text {st }}, 2^{\text {nd }}$ and $3^{\text {rd }}$ route

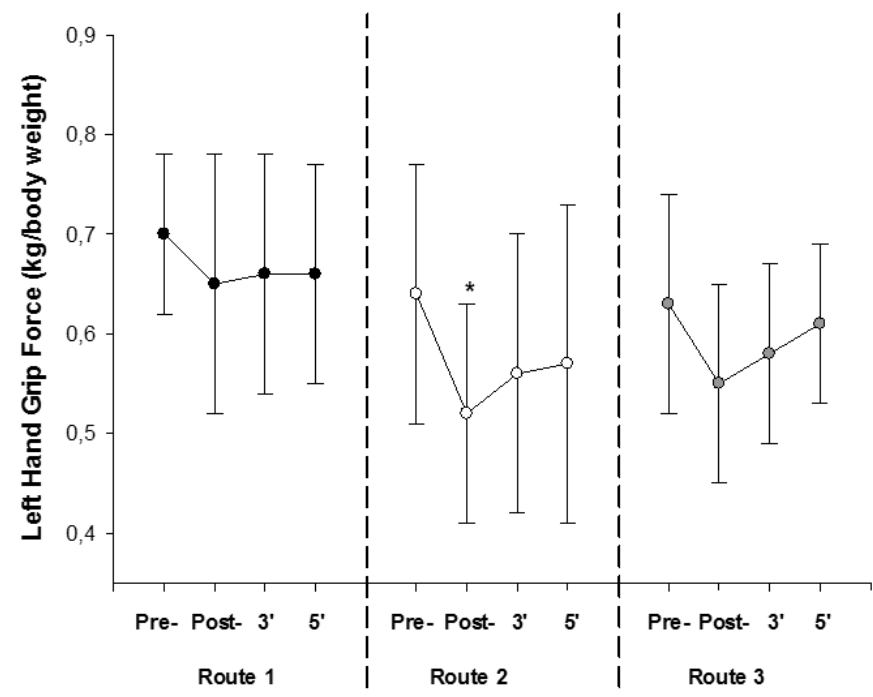

* - significantly lower than pre-climbing values $(\mathrm{p}<0.05)$.

Figure 4. Mean values $( \pm \mathrm{SD})$ of the left hand grip force values preclimbing $\left(\mathrm{HG}_{\mathrm{Pre}}\right)$ and post-climbing $\left(\mathrm{HG}_{\text {Post }}\right), 3^{\text {rd }}$ minute $\left(\mathrm{HG}_{3}\right)$ and $5^{\text {th }}$ minute $\left(\mathrm{HG}_{5}\right)$ after climbing in $1^{\text {st }}, 2^{\text {nd }}$ and $3^{\text {rd }}$ route

indicate that holds were smaller or the routes were overhanging. In addition, the climbing ability of the participants between the two studies may be an important factor as well. Moreover, there was no other information about the qualification route in Gaspari's study. In our study, qualification route was 27 holds and $6 a$ in French-sport scale. In general, most of the route setters tried not to design routes with single hard moves that require maximal power, but aimed to design more homogenous routes which get gradually harder from the beginning to the top $[6,26]$. This way, it became possible to determine athletic performance and to increase visual pleasure of the spectators. In our study, climbers' success rates, when considering the num- 
ber of holds as a climbing performance, were 100, 80 and 54\% for the $1^{\text {st }}, 2^{\text {nd }}$ and $3^{\text {rd }}$ route, respectively. All of the participants climbed the first route that was the easiest route with 27 holds (6a route). Four of them climbed the second route successfully and the mean success was $20.0 \pm 5.5$ of 25 holds (6c route). There was no top on the last route even though two of them fell from very close to the top and the mean success was $14.1 \pm 8.0$ of 28 holds route ( $7 a+$ route). Thus, the number of holds reached at the end of the climbing may be useful information to evaluate the intensity of the exercise in sport climbing.

The increase in lactic acid concentration is an important indicator of the lactic anaerobic energy system. It has been suggested that this is due to isometric contractions of the upper body and especially the forearms in sport climbing [21, 27]. Mermier et al. tested climbers on three different routes which were characterized as very easy (3+ French Sport, 6 IRCRA scale), moderate ( 5 French Sport, 9 IRCRA scale) and difficult (6b+ French Sport, 14 IRCRA scale) [3]. These routes were much easier than the routes of our study. The angle of the climbing wall and smaller-lesser hand and footholds were used to identify the difficulty of the trials and there was no other information about the number of holds in Mermier's study. Although there are some similarities with lactate increase pattern for different grade climbing routes, lactate concentrations were measured to be higher in our study. This difference in lactate concentration between the two studies may be due to the methodology. Mermier et al. used a $6.35 \mathrm{~m}$ high climbing wall and each trial took five minutes to complete (up and down with top rope climbing technique). It is well known that there are some determinants affecting climbing grade such as height and angle of the climbing wall, characteristics of the route, quality, and type or grip techniques of the holds [11,30]. Even though climbing on a short wall with very low grades is not enough to reach high plasma lactate concentration, up-and-down climbing with toprope climbing for five minutes might be used to accumulate lactate of the climbers in Mermier's study. Although climbing methodology in Mermier's study may express a model that can be used to measure physiological variables, it may not simulate the actual climbing due to the up-and-down climbing technique.

In contrast to our findings, Mermier et al. found a higher accumulation in post-climbing lactate with an increase in the routes' grade where all post-climbing lactate concentrations were significantly different from each other. The only significant difference found in our study was between the first and second routes' post-climbing lactate concentration. This situation may be attributed to the performance sustainability of the participants. All of the climbers were successful on the first route, while the ratio of $C P$ decreased in the second and third routes ( 80 and $54 \%$, respectively). In other words, a significant increase in lactate did not prevent climbers from continuing their climbing in the first route. Even though the third route was the hardest one in the competition, a decline in climbing performance, i.e. least holds reached by the climbers, may be able to explain the lower post-climbing lactate concentration compared to the second route.

A similar pattern of changes in HGF values in all the routes may indicate that HGF is distinctively affected by climbing. There are many studies that examine HGF levels of climbers $[28,29]$. It is also documented that a decrease in post-climb HGF may vary independently of a significant increase in lactate concentration [19]. In our study, in accordance with Watts et al., HGF seems to change regardless of lactate. In the first route, although there was a significant increase in lactate concentration,
HGF did not show any significant change. Presumably, this may be as a result of the difficulty of the first route being lower than the participants' self-reported climbing ability level which was $14.5 \pm 3.5$ and $17.1 \pm 4.0$ (IRCRA scale) on-sight and red-point, respectively. On the other hand, the grades of the competition routes were 11,15 and 18 (IRCRA scale) for the first, second and third routes, respectively. It is apparent that the difficulty level of the first route is quite lower than the participants' self-reported climbing ability. When matching the grades of the routes with the personal climbing abilities, it is obvious that the second route is even closer to on-sight climbing performance limits of the participants. On the other hand, last route's grade is somewhat higher than most of the participants' self-reported climbing abilities. As it was mentioned in the study of Schöffl et al., those climbers with different climbing abilities may have performance differences on the same climbing routes as physiological responses [6]. Another possible explanation to HGF reduction may be related to the grip technique of the holds that is too important to ignore in climbing [30]. Handholds of the first route may not be hard enough for a significant decline in forearm muscle strength. In contrast to the first one, HGF of the climbers decreased dramatically in the second route when the type of holds was changed without interfering with the number of holds or height and angle of the wall. A similar condition is also apparent on the third route. While the number of holds between the routes was similar, in the third route, the most difficult route of the competition, the significant difference in climbing performance may possibly be related to the gripping type of the holds.

Resting strategies may also be of great importance in the case of repetitive climbs, such as in competitions. Every single move may have a considerable effect on podium ranking especially in prestigious organizations with larger participation. In the present study, climbers' resting strategies were not studied. However, measurements of pre-climbing lactate, HGF and heart rate values were close enough to the base-line level which may explain that the climbers rested well before the next climb. It is well documented that active rest after climbing is a more effective method than resting passively [5, 19, 22, 23]. Watts et al. reported that lactate level remains elevated even after twenty minutes of passive recovery immediately after climbing [24]. This shows that resting even for twenty minutes passively is not the key to faster recovery. That is why, according to the results, climbers in our study may not be completely rested passively or thirty minutes of self-resting strategy is sufficient to recover for lactate clearance and HR. But a total decrease in HGF may indicate that the cumulative effect of fatigue continues and climbers did not complete the full recovery process. Therefore, it may be insufficient to interpret fatigue in sport climbing only with lactate, which is the end product of anaerobic glycolysis. In this sense, factors such as intracellular inorganic phosphate and an increase in ADP concentration, ions and calcium imbalances, a decrease in phosphagen storage may all play a role in the loss of strength and failing in sport climbing. With all this in mind, it is still debated whether twenty minutes of active rest or thirty minutes of self-resting strategy is more effective in sport climbing.

\section{Conclusions}

We conclude that there are noticeable changes in some physiological variables such as lactate concentration and heart rate in comparison to pre-climbing values during the three climbing trials. However, it is also seen that some similar chang- 
es in handgrip force need to be taken into consideration. In sport climbing performance, sustainable anaerobic endurance may be more important than maximal handgrip force. It is necessary to carry out future studies explaining how anaerobic endurance changes in elite and sub-elite climbers. Moreover, further research is required to determine the components of the high level climbing performance especially in a competitive setting.

\section{References}

1. Baláš J., Giles D., Chrastinová L., Kárníková K., Kodejška J. et al. (2017). The effect of potential fall distance on hormonal response in rock climbing. Journal of Sports Sciences 35(10), 989-994. DOI: 10.1080/02640414.2016.1206667.

2. Gajewski J., Hübner-Woźniak E., Tomaszewski P., Sienkiewicz-Dianzenza E. (2009). Changes in Handgrip force and blood lactate as response to simulated climbing competition. Biology of Sport 26(1), 13-21. DOI: 10.5604/20831862. 890171.

3. Mermier C.M., Robergs R.A., McMinn S.M., Heyward V.H. (1997). Energy expenditure and physiological responses during indoor rock climbing. British Journal of Sports Medicine 31(3), 224-228. DOI: 10.1136/bjsm.31.3.224.

4. Draper Draper N., Jones G.A. , Fryer S., Hodgson C.I., Blackwell G. (2010) Physiological and psychological responses to lead and top rope climbing for intermediate rock climbers. European Journal of Sport Science 10(1), 13-20. DOI: 10.1080/17461390903108125.

5. Draper N., Bird E.L., Coleman I., Hodgson C. (2006). Effects of active recovery on lactate concentration, heart rate and RPE in climbing. Journal of Sports Science and Medicine 5(1), 97-105.

6. Schöffl V.R., Möckel F., Köstermeyer G., Roloff I., Küppers T. (2006). development of a performance diagnosis of the anaerobic strength endurance of the forearm flexor muscles in sport climbing. International Journal of Sports Medicine 27(3), 205-211. DOI: 10.1055/s-2005-837622.

7. Cheung W.W., Tong T.K., Morrison A.B., Leung R.W., Kwok Y., Wu S. (2011). Anthropometrical and physiological profile of Chinese elite sport climbers. Medicina Sportiva 15(1), 2329. DOI: 10.2478/v10036-011-0007-z.

8. Michailov M.L., Morrison A., Ketenliev M.M., Pentcheva B.P. (2015). Sport-specific upper-body ergometer test for evaluating submaximal and maximal parameters in elite rock climbers. International Journal of Sports Physiology and Performance 10(3), 374-380. DOI: 10.1123/ijspp.2014-0160.

9. Sheel A.W. (2004). Physiology of sport rock climbing. British Journal of Sports Medicine 38(3), 355-359. DOI: 10.1136/ bjsm.2003.008169.

10. Draper N., Brent S., Hale B., Coleman I. (2006). The influence of sampling site and assay method on lactate concentration in response to rock climbing. European Journal of Applied Physiology 98(4), 363-372. DOI: 10.1007/ s00421-006-0289-3.

11. Quaine F., Vigouroux L. (2004). Maximal resultant four fingertip force and fatigue of the extrinsic muscles of the hand in different sport climbing finger grips. International Journal of Sports Medicine 25(8), 634-637.

12. Grant S., Hasler T., Davies C., Aitchison T.C., Wilson J., Whittaker A. (2001). A comparison of the anthropometric, strength, endurance and flexibility characteristics of female elite and recreational climbers and non-climbers. Journal of Sports Science 19(7), 499-505. DOI: 10.1080/026404101750238953.
13. Emiliano C., Veicsteinas A., Esposito F. (2008). Force control during fatiguing contractions in elite rock climbers. Sport Sciences for Health 4(3), 37-42. DOI: 10.1007/s11332008-0065-3.

14. Draper N., Giles D., Schöffl V., Fuss F.K., Watts P. et al. (2016). Comparative grading scales, statistical analyses, climber descriptors and ability grouping: International Rock Climbing Research Association position statement. Sport Technology 8(3-4), 88-94. DOI:10.1080/19346182.201 5.1107081.

15. Phillips K.C., Sassaman J.M., Smoliga J.M. (2012) Optimizing rock climbing performance through sport-specific strength and conditioning. Strength and Conditioning Journal 34(3), 1-18. DOI: 10.1519/SSC.0b013e318255f012.

16. Fryer S., Giles D., Palomino I.G., Puerta A.O., Romero V.E. (2018). Hemodynamic and cardiorespiratory predictors of sport rock climbing performance. Journal of Strength and Conditioning Research 32(12), 3534-3541. DOI: 10.1519/ JSC.0000000000001860.

17. Harriss D.J., Atkinson G. (2015). Ethical standards in sport and exercise science research: 2016 update. International Journal of Sports Medicine 36(14), 1121-1124. DOI: 10.1055/s0035-1565186.

18. The International Federation of Sport Climbing (2017). Rule Book. Retrieved January 23, 2020, from https://www. ifsc-climbing.org/index.php/world-competition/rules.

19. Watts P.B., Daggett M., Gallagher P., Wilkins B. (2000). Metabolic response during sport rock climbing and the effects of active versus passive recovery. International Journal of Sports Medicine 21(3), 185-190. DOI: 10.1055/s-2000-302.

20. Hand Dynamometer (2004). User Instructor. Lafayette Instrument Company.

21. Booth J., Marino F., Hill C., Gwinn T. (1999). Energy cost of sport rock climbing in elite performers. British Joural of Sports Medicine 33(1), 14-18. DOI: 10.1136/bjsm.33.1.14.

22. Valenzuela P.L., Villa P., Ferragut C. (2015). Effect of two types of active recovery on fatigue and climbing performance. Journal of Sports Science and Medicine 14(4), 769-775.

23. Corder K.P., Potteiger J.A., Nau K.L., Figoni S.F., Hershberger S.L. (2000). Effects of active and passive recovery conditions on blood lactate, rating of perceived exertion, and performance during resistance exercise. Journal of Strength and Conditioning Research 14(2), 151-156.

24. Watts P., Newbury V., Sulentic J. (1996). Acute changes in handgrip strength, endurance, and blood lactate with sustained sport rock climbing. The Journal of Sports Medicine and Physical Fitness 36(4), 255-260.

25. Gáspari A.F., Berton R., Lixandrão M.E., Perlotti .P, Chacon-Mikahil M.P.T., Bertuzzi R. (2015). The blood lactate concentration responses in a real indoor sport climbing competition. Science and Sports 30, 228-231.

26. Geus B., O’Driscoll S.V., Meeusen R. (2006). Influence of climbing style on physiological responses during indoor rock climbing on routes with the same difficulty. European Journal of Applied Physiology 98(5), 489-496. DOI: 10.1007/ s00421-006-0287-5.

27. Ozimek M., Staszkiewicz R., Rokowski R., Stanula A. (2016). Analysis of tests evaluating sport climbers' strength and isometric endurance. Journal of Human Kinetics 53, 249-260. DOI: 10.1515/hukin-2016-0027.

28. Gürer B., Yildiz M.E. (2015). Investigation of sport rock climbers' handgrip strength. Journal of Biology of Exercise 1l(2), 55-57. DOI:10.4127/jbe.2015.0092. 
29. Lopera M., Porcari J.P., Steffen J., Doberstein S., Foster C. (2011). The Effect of indoor rock climbing on strength, endurance and flexibility characteristics in novice climbers. Theories $\mathcal{E}$ Applications the International 1(1), 79-91.

30. Amca A.M., Vigouroux L., Aritan S., Berton E. (2012). Effect of hold depth and grip technique on maximal finger forces in rock climbing. Journal of Sports Sciences 30(7), 669-677. DOI: 10.1080/02640414.2012.658845.

Submitted: August 20, 2021

Accepted: September 23, 2021 